\title{
TRANSPLANTE RENAL CRUZADO EM PORTUGAL - UM EXEMPLO DE SUCESSO
}

\author{
Living Kidney Paired Exchange Transplant Program in Portugal - a successful example
}

\author{
Catarina Isabel Ribeiro ${ }^{1,2}$, Nicole Pestana $^{1,3}$, Filipa Silva1, Manuela Almeida1, \\ Leonídio Dias', Miguel Relvas", Susana Sampaio4, João Godinho5, Ana Gaspar ${ }^{5}$, Domingos Machado5, \\ Catarina Teixeira ${ }^{6}$, Lídia Santos ${ }^{6}$, Sandra Tafulo ${ }^{7}$, Fernando Nolasco ${ }^{8}$, António Castro Henriques ${ }^{1}$, António Cabrita ${ }^{1}$
}

\section{RESUMO}

Até $30 \%$ dos pares de dador vivo não são transplantados por incompatibilidade do grupo ABO e/ou do sistema Human Leukocyte Antigen (HLA). Os programas de doação renal cruzada surgiram como uma estratégia para tentar ultrapassar estas barreiras. Em Portugal o Programa Nacional de Doação Renal Cruzada (PNDRC) foi legislado em 2010 e o primeiro transplante renal cruzado ocorreu em 2013. Até ao momento foram efetuados 22 transplantes deste tipo. Objetivo: O presente trabalho visa avaliar as caraterísticas e perfil evolutivo dos doentes submetidos a transplante renal cruzado em Portugal. Métodos: Os autores apresentam um estudo observacional retrospetivo com análise dos respetivos doentes. Resultados: Da amostra total, a maioria dos recetores era do sexo masculino (55\%), com idade mediana 53 anos. A poliquistose renal foi a etiologia da doença renal mais comum (18\%) e a maioria dos doentes encontrava-se previamente em programa crónico de hemodiálise (68\%). Três doentes apresentaram Calculated Panel Reactive Antibody (PRAc) superior a $98 \%$ e 10 PRAc superior a $80 \%$. Foi realizada indução de imunossupressão com Anti-Thymocyte Globulin (ATG) em 50\% dos doentes e imunomodulação com Rituximab e/ou plasmaferese em $15 \%$. Todos os recetores evoluíram com função imediata do enxerto. Não se registaram complicações major, com eventos minor em $15 \%$. Num tempo mediano de followup de 27 [2-46] meses, não se verificou nenhum caso de rejeição celular aguda e apenas um de rejeição humoral. As sobrevidas do dador e recetor foram ambas $100 \%$. Conclusão: A apresentação destes resultados preliminares excelentes visa estimular o aumento do número de pares a incluir no PNDRC e um maior número de transplantes efetuados no programa. Tal como uma parte significativa desta amostra, o transplante renal cruzado pode constituir uma possibilidade para doentes com incompatibilidade do sistema HLA e/ou do grupo ABO. A doação renal cruzada em muito engrandece a doação em vida, oferecendo a pares incompatíveis e selecionados, uma oportunidade de transplantação renal com sucesso.

Descritores: Insuficiência renal crónica; Transplante de Rim; Histocompatibilidade; Portugal.

Instituições:

${ }^{1}$ Centro Hospitalar Universitário do Porto, Porto - Portugal

${ }^{2}$ Centro Hospitalar de Vila Nova de Gaia - Espinho, Vila Nova de Gaia - Portugal

${ }^{3}$ Hospital Central do Funchal, Funchal - Portugal

${ }^{4}$ Centro Hospitalar Universitário de São João, Porto - Portugal

${ }^{5}$ Centro Hospitalar Lisboa Ocidental, Lisboa - Portugal

${ }^{6}$ Centro Hospitalar Universitário de Coimbra, Coimbra - Portugal

${ }^{7}$ Instituto Português do Sangue e da Transplantação, IP, Porto Portugal

${ }^{8}$ Centro Hospitalar Lisboa Central, Lisboa - Portugal

\section{Correspondência:}

Catarina Isabel Correia Dias Ribeiro

Rua da Palmeira, $\mathrm{n}^{\circ} 1471^{\circ}$ esquerdo Laborim, CP 4430-163,

Vila Nova de Gaia, Porto - Portugal

Tel.: +351 910771837

E-mail: catarina.isabel.ribeiro@gmail.com

Recebido em: 30/04/19

Aceito em: 28/05/2019

\section{INTRODUÇÃO}

No doente portador de doença renal crónica classificada em grau 5 pela Kidney Disease Improving Global Outcomes o transplante renal é a terapêutica substitutiva da função renal que se associa a maior qualidade de vida e sobrevida. Em resposta à constante necessidade e escassez de órgãos, a dádiva de rim em vida, complementar à dádiva post mortem, constitui uma alternativa atualmente largamente utilizada., ${ }^{1,2}$ Contudo até $30 \%$ dos pares de dador vivo não são transplantados por incompatibilidade do grupo sanguíneo $A B O$ e/ou presença de anticorpos contra o sistema HLA do dador. A doação renal cruzada constitui uma alternativa para tentar ultrapassar algumas destas barreiras, oferecendo 
a doentes selecionados a possibilidade de transplante. Caso se confirme a compatibilidade entre pares, o dador de um dos pares poderá doar o rim ao elemento recetor do outro par. Neste contexto, com vista a melhorar a resposta às necessidades dos doentes candidatos, e homologado pela Portaria $n^{\circ} 802 / 2010$ de 23 de Agosto em Diário da República, surgiu o PNDRC em Portugal.

Os critérios para seleção do par a integrar no PNDRC incluem a incompatibilidade de grupo sanguíneo ABO, a positividade de crossmatch por citotoxicidade dependente do complemento e/ou citometria de fluxo e a presença de Donor-Specific Antibodies (anti-DSA). Como critérios de exclusão consideram-se a contra-indicação para transplante renal, a ausência de consentimento informado assinado por todos os elementos do par e um parecer desfavorável da Entidade de Verificação da Admissibilidade da Colheita para Transplante..$^{3,4}$

Em Portugal, o transplante renal cruzado foi legislado em 2010 e três anos depois ocorreu o primeiro transplante deste tipo. No PNDRC foram inscritos um total de 100 pares, dos quais 37 estão atualmente ativos, em cinco dos Centros Hospitalares envolvidos: CHUP, Centro Hospitalar de São João, Centro Hospitalar Universitário de Coimbra, Centro Hospitalar Lisboa Central e Centro Hospitalar Lisboa Ocidental. Até ao momento há registo de 22 transplantes renais cruzados realizados em Portugal. ${ }^{5}$

\section{OBJETIVO}

O presente trabalho teve como principal objetivo avaliar as características e perfil evolutivo dos doentes submetidos a transplante renal cruzado em Portugal.

\section{MÉTODOS}

Os autores realizaram um estudo observacional retrospetivo multicêntrico, que envolveu a análise dos 22 pares dador/recetor envolvidos nos transplantes renais cruzados efetuados em Portugal nos últimos seis anos, em quatro dos cinco Centros Hospitalares integrados no PNDRC. Foi realizada a colheita de dados por consulta dos processos clínicos dos respetivos doentes, procedendo-se posteriormente à análise descritiva dos mesmos.

O estudo estatístico foi efetuado através do software informático IBM SPSS Statistics $®$ V.26. Para a análise descritiva foram apresentadas médias e desvios-padrão das variáveis contínuas com simetria das distribuições; no caso das distribuições assimétricas foi utilizada a mediana, com menção dos valores mínimos e máximos.

\section{RESULTADOS}

Os autores partiram de uma amostra de 22 pares dador/ recetor inscritos no PNDRC, com tempo mediano de follow-up de 27 [2 - 46] meses. Prévia à inscrição no PNDRC, foi efetuada uma avaliação global da situação socioeconômica dos pares, considerando-se que todos eles reuniam condições razoáveis e satisfatórias que permitissem uma adesão ao protocolo, com cumprimento das orientações nele implicadas.

Os pares foram constituídos por elementos de Centros Hospitalares diferentes, tendo todos os transplantes sido realizados em simultâneo, no mesmo dia. Dos 22 pares transplantados, 16 tinham relação de parentesco e os restantes pares eram cônjuges. Os transplantes foram realizados somente entre 2 pares específicos (Par 1 e Par 2) na forma de doação cruzada.

Relativamente às caraterísticas gerais dos recetores a mediana de idade obtida foi 53 [31 - 71] anos, com 55\% $(n=12)$ dos doentes do género masculino. A etiologia da doença renal mais prevalente nesta amostra foi a doença renal poliquística em $18 \%$ dos casos $(n=4)$, seguida da glomerulonefrite crónica e da nefropatia diabética em $14 \%(n=3)$. Mais de $60 \%$ dos doentes $(n=15)$ estava previamente em programa crónico de hemodiálise, contrastando com quase $30 \% \quad(n=6)$ em diálise peritoneal. Apenas um doente realizou transplante renal preemptive [Tabela 1].

Em $82 \%$ dos casos $(n=18)$ o motivo de inclusão no PNDRC foi a presença de anti-DSA, com apenas 3 casos de incompatibilidade do grupo ABO. Três doentes apresentaram PRAc superior a $98 \%$ e 10 PRAc superior a $80 \%$. Foi realizada indução de imunossupressão com ATG, Tacrolimus, Micofenolato Mofetil e corticóide em $50 \%$ dos doentes $(n=11)$. A imunomodulação com Rituximab e/ou plasmaferese foi necessária em quase $15 \%$ dos casos $(n=3)$.

Da análise do período pós-transplante obteve-se uma função imediata do enxerto renal na totalidade dos doentes $(n=22)$, com creatinina sérica média à data de alta e à data da última consulta de Nefrologia de 1,26 \pm 0.53 e $1,17 \pm 0.39 \mathrm{mg} / \mathrm{dL}$, respetivamente. A média do ratio proteínas-creatinina em amostra de urina ocasional foi respetivamente $0,72 \pm 0.74$ e $0,16 \pm 0.15 \mathrm{~g} / \mathrm{g}$.

No pós-operatório imediato, verificaram-se três complicações minor (duas estenoses da anastomose e uma uretero-hidronefrose), sem registo de complicações major. Relativamente às situações de rejeição aguda, em apenas um doente verificou-se uma rejeição mediada por anticorpos, com resposta plena à terapêutica instituída. Não se registaram eventos de rejeição celular. Findo o tempo de follow-up, a sobrevida do dador e recetor foram ambas de $100 \%$. 
Tabela 1: Caraterísticas gerais dos recetores

\begin{tabular}{|c|c|}
\hline Variável & Valor $(\mathrm{N}=\mathbf{2 2})$ \\
\hline Idade, (MED, anos) & $53[31-71]$ \\
\hline \multicolumn{2}{|l|}{ Género, n (\%) } \\
\hline Masculino & $12(54 \%)$ \\
\hline Feminino & $10(46 \%)$ \\
\hline \multicolumn{2}{|l|}{ Causa da doença renal, n (\%) } \\
\hline Doença renal poliquística & $4(18 \%)$ \\
\hline Glomerulonefrite crónica & $3(14 \%)$ \\
\hline Nefropatia diabética & $3(14 \%)$ \\
\hline Nefropatia de IgA & $2(9 \%)$ \\
\hline Nefropatia hereditária & $2(9 \%)$ \\
\hline Indeterminada & $4(18 \%)$ \\
\hline Outras & $4(18 \%)$ \\
\hline Tempo em diálise ( $\bar{n}$, anos) & $5 \pm 5.0$ \\
\hline Hemodiálise, n (\%) & $15(68 \%)$ \\
\hline Diálise Peritoneal, n (\%) & $6(27 \%)$ \\
\hline Transplante renal preemptive, $\mathrm{n}(\%)$ & $1(5 \%)$ \\
\hline Diurese residual, n (\%) & $12(54 \%)$ \\
\hline \multicolumn{2}{|l|}{ Grupo sanguíneo, n (\%) } \\
\hline A & $12(54 \%)$ \\
\hline B & $1(5 \%)$ \\
\hline $\mathrm{AB}$ & $1(5 \%)$ \\
\hline $\mathrm{O}$ & $8(36 \%)$ \\
\hline \multicolumn{2}{|l|}{ Serologias víricas, n (\%) } \\
\hline Antigénio HBs + & 0 \\
\hline $\mathrm{HCV}+$ & 0 \\
\hline HIV 1 e $2+$ & 0 \\
\hline Citomegalovírus IgG + & $15(68 \%)$ \\
\hline Epstein-Barr IgG + & $14(64 \%)$ \\
\hline
\end{tabular}

MED: mediana; $\bar{n}$ : média; AgHBs: HCV: hepatite C; HIV: vírus da imunodeficiência humana; +: positivo

\section{DISCUSSÃO}

A incidência crescente de doença renal crônica a carecer de terapêutica substitutiva da função renal é uma realidade. Face ao exposto, nas últimas décadas, Portugal apresentou uma atividade também esta crescente, ainda que com distribuição variável, na área da transplantação renal. ${ }^{5,6}$ Contudo, e apesar de esforços mantidos e da cooperação entre centros, a escassez de órgãos para transplante mantem-se ainda um fator limitante para a realização de um maior número de transplantes. Nesse sentido, ganhou ênfase a transplantação renal em vida, com a implementação do programa de $\mathrm{ABO}$ incompatível e com a promoção e homologação dos programas de doação cruzada. ${ }^{3}$

Com o presente trabalho os autores reforçam a importância do transplante renal cruzado como uma oportunidade a oferecer a doentes hipersensibilizados com PRAc elevado e potenciais dadores incompatíveis, à semelhança do que se verificou com uma parte significativa da presente amostra. Hoje está bem estabelecido que os programas de transplantação renal cruzada são logisticamente mais complexos, mas medicamente mais simples que os programas de dessensibilização. Para além disso, as estratégias de dessensibilização e de transplantação renal $A B O$ incompatível deverão ser sempre consideradas como complementares destes programas de transplante cruzado.

Sabe-se que o sucesso do PNDRC se encontra largamente dependente do número de pares dador/ recetor nele inscrito. Assim a apresentação dos resultados obtidos neste trabalho projeta-se como um estímulo para a inscrição de mais pares que deles possam beneficiar. A acrescer a isso, a inclusão de dadores e recetores compatíveis com elevados mismatches, bem como a aceitação de dadores altruístas, poderão ser contributos importantes para o alargamento futuro destes programas..$^{4,5}$ À luz de Ferrari $\mathrm{P}$, et al., e perante elevados mismatch de epletos, a participação de pares dador/recetor compatíveis e a alocação baseada no crossmatch virtual poderão também fornecer um melhor e mais adequado perfil imunológico. ${ }^{7}$

Ainda a motivar a sua expansão, admite-se crescente a importância da inclusão dos pares inscritos no PNDRC em programas internacionais e com valores similares, do qual é exemplo o South Alliance. ${ }^{5,8}$

O presente trabalho é pioneiro no país, não existindo até ao momento publicações nacionais com abordagem da temática.

\section{CONCLUSÃO}

Os autores assumem e destacam a afirmação da doação renal cruzada em Portugal como um ponto de viragem à dádiva em vida, capaz de, desta forma, oferecer a pares selecionados a possibilidade de transplantação renal com sucesso. Dos resultados apresentados em muito se enaltecem as excelentes taxas de sobrevida global e função imediata do enxerto renal a motivar o acréscimo de pares a integrar futuramente o PNDRC. 


\section{ABSTRACT}

Up to $30 \%$ of living donor pairs are not transplanted for mismatch ABO group and/or system Hu-man Leukocyte Antigen (HLA). Kidney paired exchange donation national programs emerged as a strategy to try to overcome these barriers. In Portugal, the Kidney Paired Exchange Donation National Program (KPEDNP) was legislated in 2010, and the first living kidney paired exchange transplant occurred in 2013. So far 22 transplants have been performed. Purpose: The present work aims to assess the characteristics and evolution of patients submitted to kidney paired ex-change transplant in Portugal. Methods: The authors present a retrospective observational study with analysis of respective patients. Results: Of the total sample, most recipients were male (55\%), with a median age of 53 years. Renal polychistosis was the etiology of the most common kidney disease (18\%) and most patients were previously on chronic hemodialysis (68\%). Three patients had calculated Panel Reactive Antibody (PRAc) higher than $98 \%$ and 10 had higher than $80 \%$ PRAc. Anti-Thymocyte Globulin (ATG) immunosuppression was induced in $50 \%$ of patients and Rituximab and/or plasmapheresis immunomodulation in 15\%. All recipients pre-sented immediate graft function. There were no major complications, with minor events at $15 \%$. At a median follow-up time of 27 [2-46] months there were no cases of acute cell rejection and only one case of humoral rejection. Donor and recipient survival rates were both $100 \%$. Conclusion: These excellent preliminary results aim to stimulate the increase in the number of pairs to include in the KPEDNP and a larger number of transplants performed in this program. As a significant part of this sample, living-kidney paired exchange transplant may be a possibility for patients with HLA and/or ABO group incompatibility. Kidney paired exchange donation enhances life donation and offer to incompatible and selected pairs an opportunity of successful kidney transplantation.

Keywords: Renal Insufficiency, Chronic; Kidney Transplantation; Histocompatibility; Portugal.

\section{REFERÊNCIAS}

1. Hart A, Smith J, Skeans M, Gustafson S, Wilk A, Robinson A, et al. OPTN/SRTR 2016 Annual Data Report: Kidney. Am J Transplant. 2018;18 Suppl 1:18.

2. O'Connor K, Delmonico F. Increasing the supply of kidneys for transplantation. Semin Dial 2005; 18:460.

3. Diário da República, 1. ${ }^{a}$ série - N. 163 - 23 de Agosto de 2010 Portaria n. ${ }^{\circ} 802 / 2010$

4. Klerk M, ljzermans J, Kranenburg L, Hilhorst M, van Busschbach J, Weimar W. Cross-over transplantation; a new national program for living kidney donations. Ned Tijdschr Geneeskd. 2004 Feb;148(9):420-3.

5. Instituto Português do Sangue e da Transplantação, IP [homepage na Internet]. Programa Nacional de Doação Renal Cruzada. [acesso em Abril de 2019]. Disponível em: http://ipst.pt/.
6. Sociedade Portuguesa de Nefrologia [homepage na Internet]. Relatório Anual do Gabinete de Registo da Sociedade Portuguesa de Nefrologia, 2018 [acesso em Abril de 2019]. Disponível em: https://www. spnefro.pt/.

7. Ferrari P, Cantwell L, Ta J, Woodroffe C, D'Orsogna L, Holdsworth R. Providing Better-Matched Donors for HLA Mismatched Compatible Pairs Through Kidney Paired Donation. Transplantation. 2017 Mar;101(3):642-8.

8. Rees M, Schnitzler M, Zavala E, Cutler J, Roth A, Irwin $\mathrm{F}$, et al. Call to develop a standard ac-quisition charge model for kidney paired donation. Am J Transplant. 2012;12:1392. 